\title{
Evaluation of the Do Bugs Need Drugs? program in British Columbia: Can we curb antibiotic prescribing?
}

\author{
Rachel M McKay MSc ${ }^{1}$, Linda Vrbova $\mathrm{MSc}^{2}$, Elaine Fuertes $\mathrm{MSc}^{2}$, Mei Chong MSc${ }^{1}$, Samara David MSc ${ }^{1}$, \\ Kim Dreher RN BSCN ${ }^{1}$, Dale Purych MD ${ }^{3,4}$, Edith Blondel-Hill MD FRCPC ${ }^{2,5}$, Bonnie Henry MD MPH FRCPC ${ }^{1,2}$, \\ Fawziah Marra BSc PharmD FCSHP ${ }^{1,2}$, Perry RW Kendall OBC MBBS MSc FRCPC ${ }^{6}$, David M Patrick MD FRCPC MHSc ${ }^{1,2}$
}

RM McKay, L Vrbova, E Fuertes, et al. Evaluation of the Do Bugs Need Drugs? program in British Columbia: Can we curb antibiotic prescribing? Can J Infect Dis Med Microbiol $2011 ; 22(1): 19-24$.

OBJECTIVE: Antibiotic resistance is accelerated by the overuse of antibiotics. Do Bugs Need Drugs? is an educational program adapted in British Columbia to target both the public and health care professionals, with the aim of reducing unnecessary prescribing. The current article presents a descriptive evaluation of the impact of the program over the first four years.

METHOD: Program implementation was measured by the amount of educational material distributed and the level of participation in educational sessions. The impact of the program was assessed by measuring changes in knowledge and prescribing habits of participating physicians, and by investigating provincial trends in antibiotic use.

RESULTS: A total of 51,367 children, assisted-living residents and health care professionals have participated in the program since its inception in the fall of 2005. Pre- and postcourse assessments of participating physicians indicated significant improvements in clinical knowledge and appropriate antibiotic treatment of upper respiratory tract infections. Overall rates of antibiotic use in the province have stabilized since 2006. The rates of consumption of fluoroquinolones and macrolides have levelled off since 2005. Utilization rates for acute bronchitis are at the same level as when the program was first implemented, but rates for other acute upper respiratory tract infections of interest have declined.

CONCLUSIONS: The Do Bugs Need Drugs? program significantly improves physician antibiotic prescription decisions and is ecologically associated with desirable change in population antibiotic consumption patterns.
Évaluation du programme Do bugs need drugs? en Colombie-Britannique : Peut-on restreindre la prescription des antibiotiques?

OBJECTIF : La résistance aux antibiotiques croît en raison de leur
surutilisation. Do bugs need drugs? est un programme mis sur pied en
Colombie-Britannique pour sensibiliser le public et les professionnels de la
santé à la surutilisation des antibiotiques. Le présent article mesure
l'impact du programme au cours de ses quatre premières années
d'application. MÉTHODE quantité de matériel éducatif distribué et du degré de participation aux séances d'information, et son impact, en fonction des changements observés sur le plan des connaissances et des habitudes de prescription des participants et des tendances provinciales quant à l'utilisation des antibiotiques.

RÉSULTATS : En tout, 51367 enfants, résidents recevant une aide à l'autonomie et professionnels de la santé ont participé au programme depuis sa mise en place à l'automne 2005. Les pré- et post-tests des médecins participants ont révélé une amélioration significative des connaissances cliniques et du recours approprié à l'antibiothérapie dans les infections respiratoires hautes. Les taux globaux d'utilisation des antibiotiques dans la province se sont stabilisés depuis 2006 et les taux d'utilisation des fluoroquinolones et des macrolides, depuis 2005. Leurs taux d'utilisation pour la bronchite aiguë se situent au même niveau que lorsque le programme a débuté, mais pour les infections aiguës des voies respiratoires hautes, ils ont diminué.

CONCLUSION : Le programme Do bugs need drugs? améliore significativement les décisions des médecins quant à la prescription des antibiotiques et est écologiquement associé à un changement souhaitable des modes de consommation des antibiotiques dans la population.

Key Words: Antibiotics; Community education; Program evaluation; Utilization

\footnotetext{
ntibiotics have had a profound impact on health by improving our ability to prevent, cure and reduce transmission of many infectious diseases (1). The increasing prevalence and geographical spread of resistant and multiresistant organisms threatens this progress (2-5). Antibiotic resistance is a naturally occurring biological phenomenon, but has been exacerbated by selective pressure caused by the use and
}

misuse of antimicrobials (6-9). Ecological studies and randomized controlled trials $(6,7,10-12)$ have confirmed the association between utilization and resistance. It has been estimated that antibiotic use is unnecessary or inappropriate in up to $50 \%$ of prescriptions in the United States and Canada $(13,14)$, and that this is largely driven by prescriptions for upper respiratory tract infections (15).

${ }^{1}$ BC Centre for Disease Control; ${ }^{2}$ University of British Columbia, Vancouver; ${ }^{3}$ BC Biomedical Laboratories Ltd; ${ }^{4}$ Fraser Health Authority,

Surrey; ${ }^{5}$ Interior Health Authority, Kelowna; ${ }^{6}$ British Columbia Ministry of Health, Victoria, British Columbia

Correspondence: Ms Rachel M McKay, BC Centre for Disease Control, 655 West 12th Avenue, Vancouver, British Columbia V5Z 4 R4.

Telephone 604-707-2534, fax 604-707-2516, e-mail Rachel.Mckay@bccdc.ca 
Infection control practices, hospital formulary policies and immunization programs have important roles to play in the containment of antimicrobial resistance $(13,16,17)$, but strategies to reduce the amount of antibiotics being unnecessarily prescribed are also essential (18). Such activities should take into account known drivers of prescribing including patient knowledge and expectation, and physician time pressure $(19,20)$. Large-scale campaigns promoting the optimization of antibiotic use have been implemented in many jurisdictions. Ecological data (21) suggest that these campaigns can be associated with decreased antibiotic consumption. Overall, such programs have proven to be most effective when they target both public and health care providers (18).

In the fall of 2005, the province of British Columbia (BC) adopted the Do Bugs Need Drugs? (DBND) program from the neighbouring province of Alberta. The DBND program aims to reduce the number of unnecessary antibiotic prescriptions by educating the public and health care professionals on the appropriate use of antibiotics, primarily focusing on acute upper respiratory tract infections. The main objective of the present article is to describe the progress and evaluation of the DBND program from September 1, 2005, to August 30, 2009. An analysis of the time series antibiotic prescribing data is presented elsewhere (22). The goal of the evaluation is to measure both process and outcomes associated with the program. The process evaluation comprises the number of participants in each arm of the program, the distribution of print material and the reach of the media campaign. Outcome evaluation includes measuring public knowledge and attitudes, and monitoring overall antibiotic consumption, class-specific antibiotic consumption and indication-specific antibiotic consumption.

\section{METHODS}

The present article describes an ecological study of the association between implementation of the DBND program and population outcome indicators.

There were two main arms of the DBND program: the public component and the health care professional education component, both of which were implemented in phases. The public education component included annual media campaigns, print material distribution, and audience-specific education curricula targeting children in daycare (two to five years of age) and their parents, grade 2 students (seven years of age) and their parents, older adults in assisted-living facilities and the general public. The print material included signs, posters, stickers, activity placemats and a parent's guide to managing common infections. The media campaigns were aired on television and radio, and advertising appeared on transit routes and vehicles. The key messages delivered by each of these means were identical:

- Wash your hands.

- Antibiotics work against bacteria, not against viruses.

- Use antibiotics wisely because bacteria can become resistant to them.

Participation in the daycare, grade 2 and assisted-living programs was recorded by the trainers and submitted to DBND. Inventory logs were maintained to track the distribution of print material, and reports were provided by the transit and media contractors, which use industrystandard methodologies to estimate the reach of these initiatives. A telephone survey was conducted by Ipsos Reid (Canada) before and after the initial launch of the program to assess knowledge and attitudes regarding the program's key messages. The objective of the public education component was to promote the key messages in an effort to improve hand hygiene behaviours and to reduce patient pressure, which can affect prescribing decisions of physicians.

The health care professional education arm of the program offered accredited courses to physicians and pharmacists, with a focus on antibiotic use, resistance and strategies to prescribe appropriately. Physicians and pharmacists who participated in the accredited continuing education programs completed pre- and postcourse learner assessments. These assessed general knowledge of resistance trends, etiology of respiratory infections and treatment options. Physicians also completed four indication-specific quizzes before and after participation in the course. These quizzes were not identified, so they could not be statistically compared before and after. Physicians completed carbon-copy prescription pads for one month preceding and one month following participation in the course. These prescription pads were used with every patient presenting with upper respiratory tract symptoms, and recorded diagnosis, nonantibiotic symptomatic recommendations, antibiotic treatment and known drug allergies. The top copy was given to the patient as a valid script, while the bottom copy (not containing identifying information) was returned to the DBND program for evaluation purposes.

In addition, health care providers, and health care and early childhood education students, were trained to deliver the public education sessions.

The objectives of the health care professional education arm of the program were to promote the key messages, specifically, to reduce antibiotic prescriptions for acute bronchitis and acute otitis media; to reduce the use of fluoroquinolones and newer macrolides (azithromycin and clarithromycin); and to reduce the overall use of antibiotics in the population.

A detailed description of the program components was beyond the scope of the present article. Contact the authors for further information or visit $<$ dobugsneeddrugs.org $>$.

\section{Antibiotic consumption}

BC PharmaNet is a provincial network that links community-based BC pharmacies to a central data system. PharmaNet provides real-time information about all prescription medications dispensed to an individual in BC, and allows pharmacists to quickly identify and warn about potentially harmful medication interactions. In 2007, more than 47 million prescription claims were processed through the system (23).

The PharmaNet data include all prescriptions dispensed via retail or online pharmacies in $\mathrm{BC}$, with the exclusion of bulk purchases by general practitioners and purchases for veterinary use. The database contains a study identifier, age, sex and drug information detailing generic name, brand name, form, strength and quantity dispensed, date of dispensing and the practitioner identifier. An anonymized data extract from PharmaNet was obtained from 1996 to 2008 by the DBND program.

Each dispensing record was then matched to the Medical Services Plan (MSP) billing system, which represents physician services remunerated on a fee-for-service basis, and includes The International Classification of Diseases - Ninth Revision diagnostic codes. The matching criteria were study identifier, practitioner identifier and the date of dispensing within five days after the date of physician service. If more than one MSP record met the matching criteria, the record with the closest date to the date of dispensing was used. Multiple MSP records due to different diagnostic codes for the same date of service were counted as separate indications for the drug dispensed.

Antimicrobials were classified according to the WHO's 5-level Anatomical Therapeutical Chemical (ATC) classification system (24). Only oral prescriptions for J01 class, ie, antibacterials for systemic use, were included in the analysis. Consumption was further broken down into six major ATC classes: J01A (tetracyclines), J01C (beta-lactam penicillins), J01D (other beta-lactam), J01E (sulfonamides/trimethoprim), J01F (macrolides) and J01M (quinolones). For the MSP-matched records, the diagnostic codes were regrouped into specific indications of interest. Data were aggregated by year for each major ATC class and/or each redefined indication. Antibiotic consumption rates were expressed in defined daily doses (DDD) per 1000 inhabitants per day (24) using the annual population estimates obtained from BC Health Data Warehouse's Population Extrapolation for Organizational Planning with Less Error (P.E.O.P.L.E.). This method has been reported previously (25).

Information on the overall cost of antimicrobials paid by $\mathrm{BC}$ residents, and by the government, was obtained from the Pharmaceutical Services Division of the BC Ministry of Health Services. 
Ethics review was granted by the University of British Columbia (Vancouver, British Columbia) for the linkage of physician billing and prescription data. Completion of the learner assessments and prescription pads were part of the program's accreditation agreement.

\section{Statistical methods}

Most of the results presented in the current study are descriptive. A onetailed paired $t$ test was used to test the hypothesis that participation in the DBND course is associated with an increase in average scores on the learner assessment. Similarly, a one-tailed $t$ test was performed to assess the change in the average of proportions of appropriate antibiotic prescriptions for specific indications written by physicians who participated in the course. The McNemar test was used to assess the effect on dichotomous variables after the course. Analyses were conducted using SPSS version 14.0 (IBM Corporation, USA) for Windows (Microsoft Corporation, USA).

\section{Target audience participation}

Since inception of the program in BC in 2005, 36,932 children have participated in the grade 2 program, 6468 children have participated in the daycare program and 159 residents have participated in the assisted-living program (the assisted-living program is the newest component to the DBND program and has been in operation for less than one year at the time of writing the present article). The DBND sessions have been attended by 7808 health care professionals, early childhood educators and assisted-living staff, of which 3186 were physicians. Seventy-eight of these physicians completed the accredited continuing education course in 2007 and 2008.

\section{Print material distribution}

Print material included stickers, signs and posters, pamphlets, a parent's guide to common infections in 10 languages, and an activity placemat for children. In the first year of the program, 584,359 print materials were distributed, with sustained distribution achieving an average of 82,199 items each year.

The Bugs $\mathcal{E}$ Drugs book (26) is a DBND-endorsed antimicrobial reference guide that provides recommendations for appropriate antibiotic use and care of patients with infectious diseases. The book was distributed to all medical, dental and pharmacy students in 2006 and to first-year students thereafter. It has also been provided to physicians, pharmacists, dentists, nurse practitioners and infection control practitioners in BC. Since 2006, 20,711 Bugs $\mathcal{E}$ Drugs books have been distributed in BC.

\section{Media campaigns \\ The media report prepared by the contractor estimated that the tele- vision campaign reached an average of $81 \%$ (range $70 \%$ to $88 \%$ ) of the primary target audience of women 25 to 54 years of age, an average of 8.3 times in each region over the four years of the program, exceeding industry standards. On average, 948 radio spots have aired during each four-week campaign. A total of 764 transit advertisements were dis- played in 2008.}

\section{Public survey}

Poor response rates (14.9\% preimplementation and $18.3 \%$ postimplementation) prevented the survey from being a valid source of information. The high cost of conducting the survey precluded making another attempt. It was decided to explore other means of assessing the impact on public knowledge.

\section{Health care professional education}

Sixty-three physicians completed the accredited continuing education course for physicians in 2008. The greatest improvement was on the otitis media quiz because the mean of correct responses increased by $18 \%$ (from $67 \%$ to $85 \%$ ) (Table 1 ). Improvements on the other quizzes
TABLE 1

Mean percentage of correct responses to quizzes by physicians before and after participating in the 2008 DBND Mainpro-C course

\begin{tabular}{lcc}
\hline Quiz topic & Preparticipation, \% & Postparticipation, \% \\
\hline Bronchitis & 70.35 & 81.43 \\
Otitis media & 66.84 & 85.16 \\
Sinusitis & 67.46 & 70.85 \\
Pharyngitis & 73.33 & 90.16 \\
\hline
\end{tabular}

DBND Do Bugs Need Drugs?

ranged from $3 \%$ (sinusitis) to $17 \%$ (pharyngitis). An assessment of general knowledge about antibiotics and resistance showed a statistically significant improvement in correct responses after the course (average increase $11.2 \% ; \mathrm{P}=0.013$ ). Improvement was particularly noted in questions that focused on the clinical management and etiology of common respiratory tract infections, and knowledge of the prevalence of resistant isolates in the community.

A summary of all recommendations by physicians who participated in the DBND course for each of the main target indications of acute bronchitis, acute otitis media, acute pharyngitis and acute sinusitis is depicted in Figure 1. Overall, there was a statistically significant decrease in the use of antibiotics for acute bronchitis (mean proportion of use $34.6 \%$ preparticipation, $21.4 \%$ postparticipation; $\mathrm{P}=0.023$ ), as well as for all indications (mean proportion of use $45.6 \%$ preparticipation, $39.2 \%$ postparticipation; $\mathrm{P}=0.019$ ) and some reduction in the use of antibiotics for acute otitis media. An encouraging reduction was noted in the use of newer macrolides (azithromycin and clarithromycin) - the mean proportion of use per physician dropped from $13.9 \%$ of prescriptions to $5.6 \%(\mathrm{P}<0.0001)$.

Of the 62 pharmacists who participated in the course in 2008, the McNemar test showed that the proportion of pharmacists who felt very comfortable contacting a prescriber to suggest a change to an antibiotic prescription increased from $25.8 \%$ before the course to $53.2 \%$ after the course $(\mathrm{P}<0.001)$. These pharmacists particularly showed improvement on questions pertaining to the correct treatment for and etiology of respiratory infections.

\section{Trends in antibiotic prescribing}

Overall pharmaceutical consumption data and MSP-PharmaNetlinked data from 1996 to 2008 were obtained. An average of $70.9 \%$ of unique PharmaNet records were successfully matched to the MSP claims database each year. The results described below refer to the complete PharmaNet data set when discussing antibiotic consumption trends, and to the MSP-PharmaNet-linked data set when discussing indication-specific consumption trends.

In the late 1990s, consumption of all antibacterials for oral systemic use in $\mathrm{BC}$ was steadily declining, reaching its lowest level in 2002. For the next three years, the rate of use increased, and has been levelling off since 2006 (Figure 2).

Before 2005, consumption of fluoroquinolones and macrolides was increasing, with rates rising from 1.41 to $1.67(18.3 \%)$ and from 2.75 to $3.56(29.5 \%)$ DDD per 1000 population per day, respectively, between 2002 and 2005. Between 2005 and 2008, however, the rate of fluoroquinolone and macrolide consumption decreased to $1.64(-1.6 \%)$ and $3.49(-2.0 \%)$ DDD per 1000 population per day, respectively (Figure 3).

In the years before the program's implementation, the consumption rate for acute otitis media was declining (Figure 4) and continued to decrease in the years following implementation of the program. The DDD rate for acute bronchitis had been declining from 1996 to 2002, at which point it began to climb again, drawing attention toward inappropriate prescribing. Between 2002 and 2005, the rate increased from 0.68 to 0.94 (39.1\%) DDD per 1000 population per day. After an initial decline in 2006, the rate in 2008 had increased again to a level 


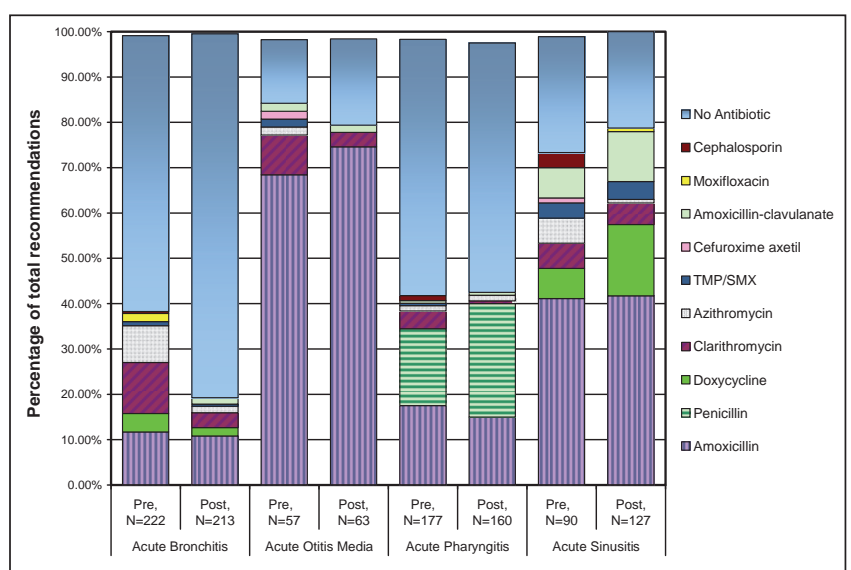

Figure 1) Antibiotic and nonantibiotic recommendations for otitis media, pharyngitis, bronchitis and sinusitis by physicians in the month before (pre) and the month after (post) participation in the Do Bugs Need Drugs? Mainpro-C course. TMP/SMX Trimethoprim/sulfamethoxazole

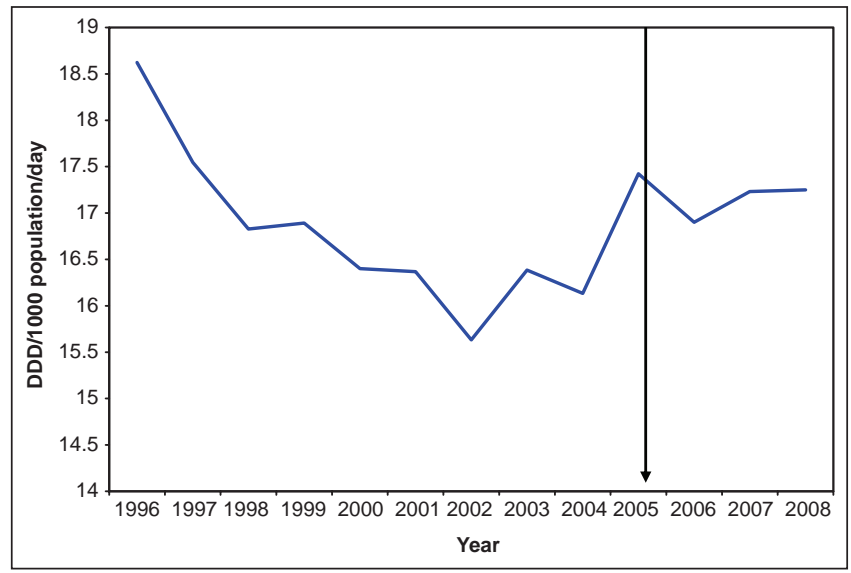

Figure 2) Daily utilization rate for all oral solid antibacterials for systemic use in British Columbia from 1996 to 2008. The arrow indicates the approximate implementation of the Do Bugs Need Drugs? program. DDD Defined daily doses

comparable with that seen in 2005 (0.95 DDD per 1000 population per day) (Figure 4).

\section{Antibiotic costs}

Antibiotic costs across the province steadily increased between 1998 and 2005. Between 2005 and 2008, there was a 4.5\% reduction in cost, totalling $\$ 3.3$ million (Figure 5).

\section{DISCUSSION}

Evaluation of the DBND implementation process indicated that this program has been effectively using a variety of means to disseminate information about antibiotic resistance to diverse target audiences, in line with accepted strategies to combat the problem of antibiotic resistance (27).

DBND is a multifaceted program that uses several methods to promote and monitor the appropriate use of antibiotics because the multidimensional approach has been shown to be most effective (18). A large-scale public poll was conducted before and after the initial media launch of the program in $\mathrm{BC}$, but low response rates and high costs prevented this from being a viable means of determining public knowledge and awareness associated with the program. While it has been

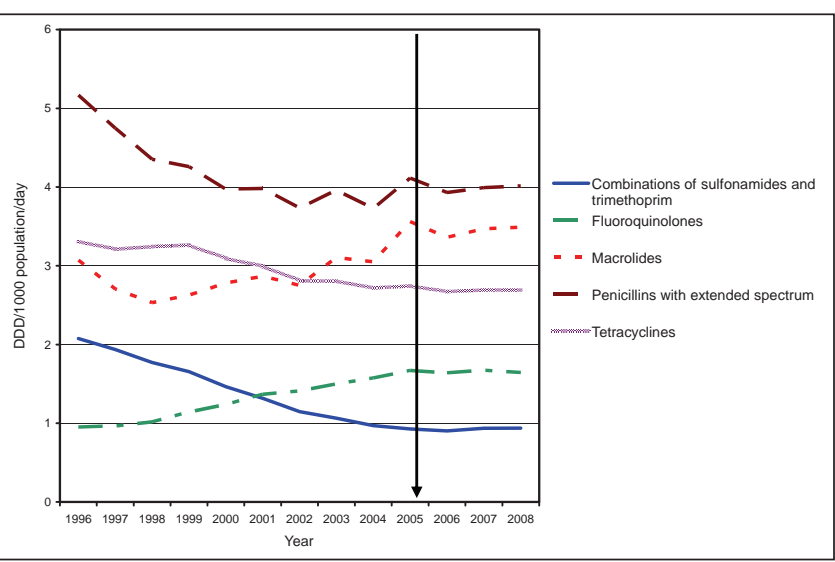

Figure 3) Consumption of select classes of antibiotics in British Columbia from 1996 to 2008. The arrow indicates the approximate implementation of the Do Bugs Need Drugs? program. DDD Defined daily doses

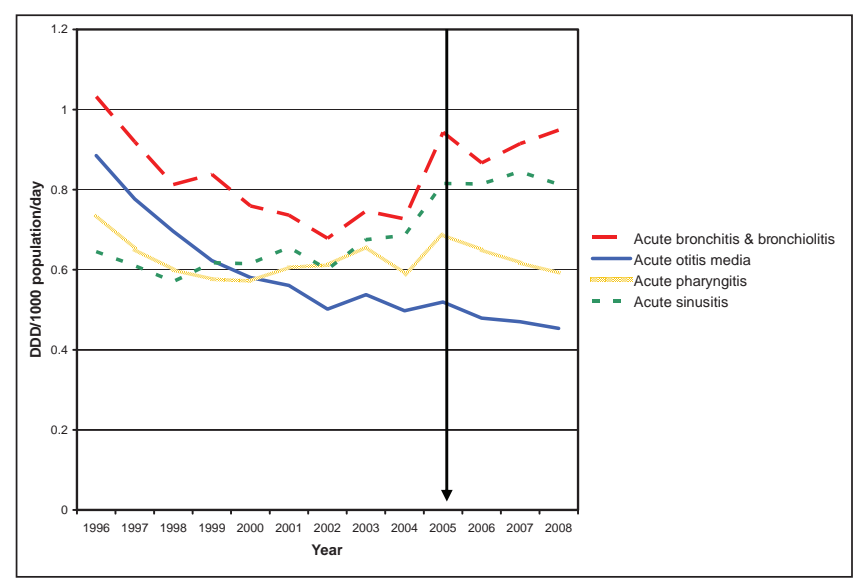

Figure 4) Overall antibiotic consumption rates in British Columbia according to indication from 1996 to 2008. The arrow indicates the approximate implementation of the Do Bugs Need Drugs? program. DDD Defined daily doses

difficult to fully measure the effect of the public component of the program, the extent of public exposure suggests that the key messages have been well distributed.

Broadening the reach of the school-based programs is necessary to ensure that the highest level of cohort participation is achieved. Children are a key target of the program because they provide a means for reaching their parents, and because reinforcing the key messages about hand washing and antibiotic resistance with youngsters will hopefully lead to lifelong behavioural changes.

The program has been increasing awareness and knowledge among health care professionals, in line with DBND's objectives. Among the most essential of measures in dealing with the problem of resistance is the improvement in the use of antimicrobials (9). In BC, trends in antibiotic utilization have stabilized since 2005; however, several trends are still concerning, particularly the increasing use of macrolides and fluoroquinolones. We have shown that significant improvements in prescribing newer macrolides can be achieved by physicians who participate in the DBND program. This would suggest that the DBND program is effective at transmitting its messages to prescribers, and that continued effort to reach more physicians is necessary before population-level changes will be apparent. We plan to capitalize on this finding by working to provide all physicians in BC with 
individualized feedback on their antibiotic prescribing patterns. This is consistent with findings that active clinician education can effectively lead to reductions in ambulatory antibiotic prescriptions (18), although the public education component remains highly important for optimal message diffusion.

Formulary control has also been shown to impact antibiotic use (28). Strategies to reduce inappropriate antibiotic prescribing should engage governmental agencies to consider the effectiveness and appropriateness of restricting antimicrobial use through formulary policy. An investigation of formulary changes did not suggest any major confounders over the study period (personal communication, Pharmaceutical Services Division, Ministry of Health Services, British Columbia).

There were several limitations to this study. One was the cost of polling the public to enable evaluation of public knowledge. Other strategies to measure the extent of message spread among the general public will need to be considered. Methods of assessing behavioural change, in addition to knowledge and awareness gained, must also be explored.

While PharmaNet is a rich source of data, it does not capture the use of antibiotics that are not dispensed at community-based pharmacies (such as samples given to patients and for hospital use). Additionally, our linkage process originated with the pharmaceutical data, so we are unable to capture individuals who received a diagnosis but did not subsequently fill an antibiotic prescription.

Due to the multifaceted nature of the program, and the lack of comparable population-based indication-specific antimicrobial utilization data from other Canadian provinces or territories, comparison of outcomes with a control group has not been possible at the population level.

Despite these limitations, the present evaluation provides a comprehensive descriptive analysis of the implementation and impact of the DBND program to date, with the results converging to suggest that strides are being made in the appropriate direction. There is an ecological association between program implementation and the stabilizing of antibiotic prescribing and costs, as well as the improvement in prescribing for certain upper respiratory tract infections. Individuallevel studies are necessary to confirm this association.

\section{REFERENCES}

1. Cohen ML. Epidemiology of drug resistance: Implications for a post-antimicrobial era. Science 1992;257:1050-5.

2. Levy SB, Marshall B. Antibacterial resistance worldwide: Causes, challenges and responses. Nature Med 2004;10:S122-9.

3. Powis J, McGeer A, Green K, et al. In vitro antimicrobial susceptibilities of Streptococcus pneumoniae clinical isolates obtained in Canada in 2002. Antimicrob Agents Chemother 2004:48:3305-11.

4. World Health Organization. Overcoming antimicrobial resistance. $<$ http://www.who.int/infectious-disease-report/2000/index.html> (Accessed on August 18, 2009).

5. Adam D. Global antibiotic resistance in Streptococcus pneumoniae. J Antimicrob Chemother 2002;50(Suppl1):1-5.

6. Riedel S, Beekmann S, Heilmann K, et al. Antimicrobial use in Europe and antimicrobial resistance in Streptococcus Pneumoniae. Eur J Clin Microbiol Infect Dis 2007;26:485-90.

7. Goossens H, Ferech M, Vander SR, Elseviers M. Outpatient antibiotic use in Europe and association with resistance: A cross-national database study. Lancet 2005;365:579-87.

8. Bronzwaer SL, Cars O, Buchholz U, et al. A European study on the relationship between antimicrobial use and antimicrobial resistance. Emerg Infect Dis 2002;8:278-82.

9. Tenover FCP, McGowan JE Jr. Reasons for the emergence of antibiotic resistance. Am J Med Sci 1996;311:9-16.

10. Van Eldere J, Mera RM, Miller LA, Poupard JA, Amrine-Madsen H. Risk factors for development of multiple-class

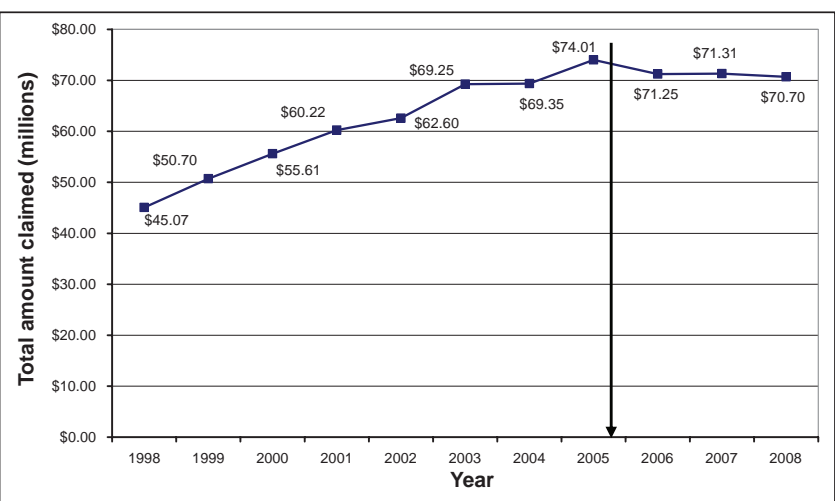

Figure 5) Total cost of antibiotic prescriptions in British Columbia from 1998 to 2008. The arrow indicates the approximate implementation of the Do Bugs Need Drugs? program

\section{CONCLUSION}

There is more progress to be made in reducing overall use of antibiotics in BC. Continued efforts are needed to increase the reach of the DBND program, via both children's programming and direct physician feedback, as well as to explore policy measures (such as formulary restriction) to support appropriate antimicrobial stewardship. Antibiotic resistance is a significant public health issue; progress is being made, but concerted efforts are still required.

ACKNOWLEDGEMENTS: The DBND team thanks the BC Ministry of Health Services, Pharmaceutical Services Division, in particular the contributions of Suzanne Taylor and Anne Nguyen. Greg Tyrrell, William Bowie, Don Low and Patricia Daly have all provided expertise in support of the DBND program. The Michael Smith Foundation for Health Research (Vancouver, British Columbia) provided a grant to fund the evaluation of the DBND program over the first three years. resistance to Streptococcus pneumoniae strains in Belgium over a 10-year period: Antimicrobial consumption, population density, and geographic location. Antimicrob Agents Chemother 2007;51:3491-7.

11. Bergman M, Huikko S, Huovinen P, Paakkari P, Seppälä H; Finnish Study Group for Antimicrobial Resistance (FiRe Network). Macrolide and azithromycin use are linked to increased macrolide resistance in Streptococcus pneumoniae. Antimicrob Agents Chemother 2006;50:3646-50.

12. Malhotra-Kumar S, Lammens C, Coenen S, Van Herck K, Goossens H. Effect of azithromycin and clarithromycin therapy on pharyngeal carriage of macrolide-resistant streptococci in healthy volunteers: A randomised, double-blind, placebo-controlled study. Lancet 2007;369:482-90.

13. Fishman N. Antimicrobial stewardship. Am J Med 2006;119(Suppl 1):S53-61.

14. Wang EE, Einarson TR, Kellner JD, Conly JM. Antibiotic prescribing for Canadian preschool children: Evidence of overprescribing for viral respiratory infections. Clin Infect Dis 1999;29:155-60.

15. Worrall G, Young B, Knight V. Inappropriate use of antibiotics for acute respiratory tract infections in a rural emergency department. Can J Rural Med 2005;10:86-8.

16. Wilton P, Smith R, Coast J, Millar M. Strategies to contain the emergence of antimicrobial resistance: A systematic review of effectiveness and cost-effectiveness. J Health Serv Res Policy 2002;7:111-7. 
17. Avorn JL, Barrett JF, Davey PG, McEwan SA, O'Brien TF, Levy SB. Antibiotic resistance: Synthesis of recommendations by expert policy groups. World Health Organization, 2001.

18. Ranji SR, Steinman MA, Shojania KG, Gonzales R. Interventions to reduce unnecessary antibiotic prescribing: A systematic review and quantitative analysis. Med Care 2008;46:847-62.

19. Belongia EA, Schwartz B. Strategies for promoting judicious use of antibiotics by doctors and patients. BMJ 1998;317:668-71.

20. Ebert SC. Factors contributing to excessive antimicrobial prescribing. Pharmacotherapy 2007;27:126S-30S.

21. Goossens H, Guillemot D, Ferech M, et al. National campaigns to improve antibiotic use. Eur J Clin Pharmacol 2006;62:373-9.

22. Fuertes E, Henry B, Marra F, Wong H, Patrick DM. Trends in antibiotic utilization in Vancouver with a community education program on antibiotic use. Can J Public Health 2010;101:304-8.
23. Ministry of Health Services. Pharmanet. <www.health.gov.bc.ca/ pharmacare/pharmanet/netindex.html 2009> (Accessed on December 9, 2009).

24. World Health Organization. WHO Collaborating Centre for Drug Statistics Methodology, 2009.

25. Marra F, Patrick DM, Chong M, Bowie WR. Antibiotic use among children in British Columbia, Canada. J Antimicrob Chemother 2006;58:830-9.

26. Blondel-Hill E, Fryters S. Bugs \& Drugs. Edmonton: Capital Health, 2006

27. Gonzales R, Corbett K, Leeman-Castillo B, et al. The "Minimizing Antibiotic Resistance in Colorado" Project: Impact of patient education in improving antibiotic use in private office practices. Health Serv Res 2005;40:101-16.

28. Marra F, Patrick DM, White R, Ng H, Bowie WR, Hutchinson JM. Effect of formulary policy decisions on antimicrobial drug utilization in British Columbia. J Antimicrob Chemother 2005;55:95-101. 


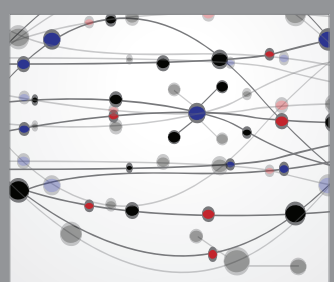

The Scientific World Journal
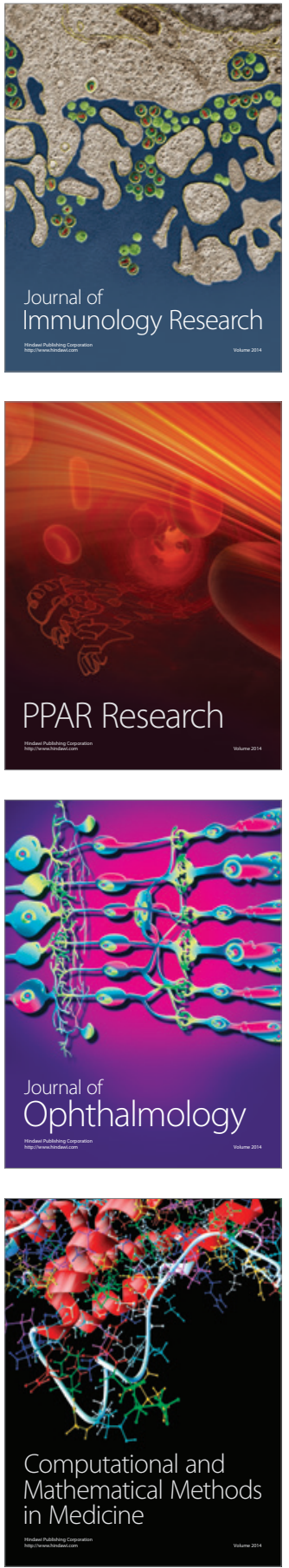

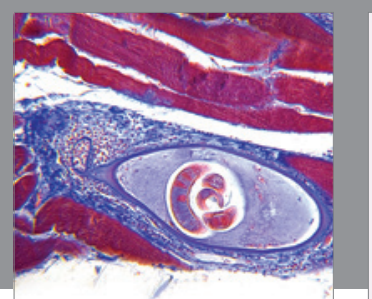

Gastroenterology Research and Practice

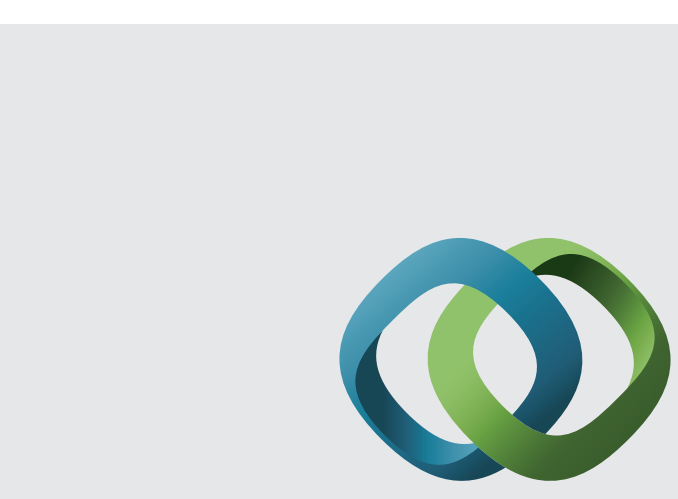

\section{Hindawi}

Submit your manuscripts at

http://www.hindawi.com
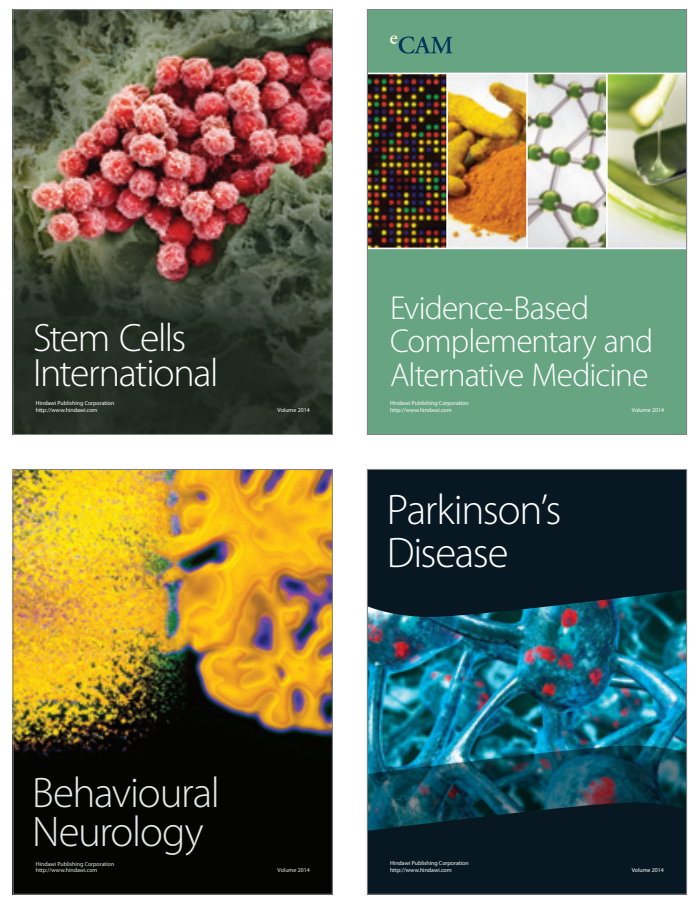
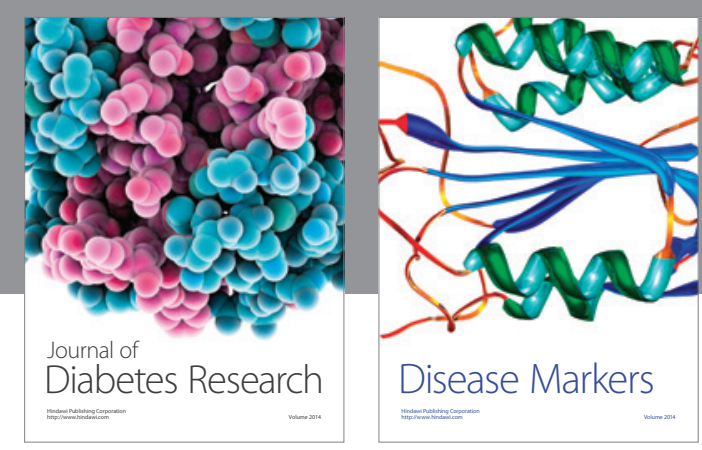

Disease Markers
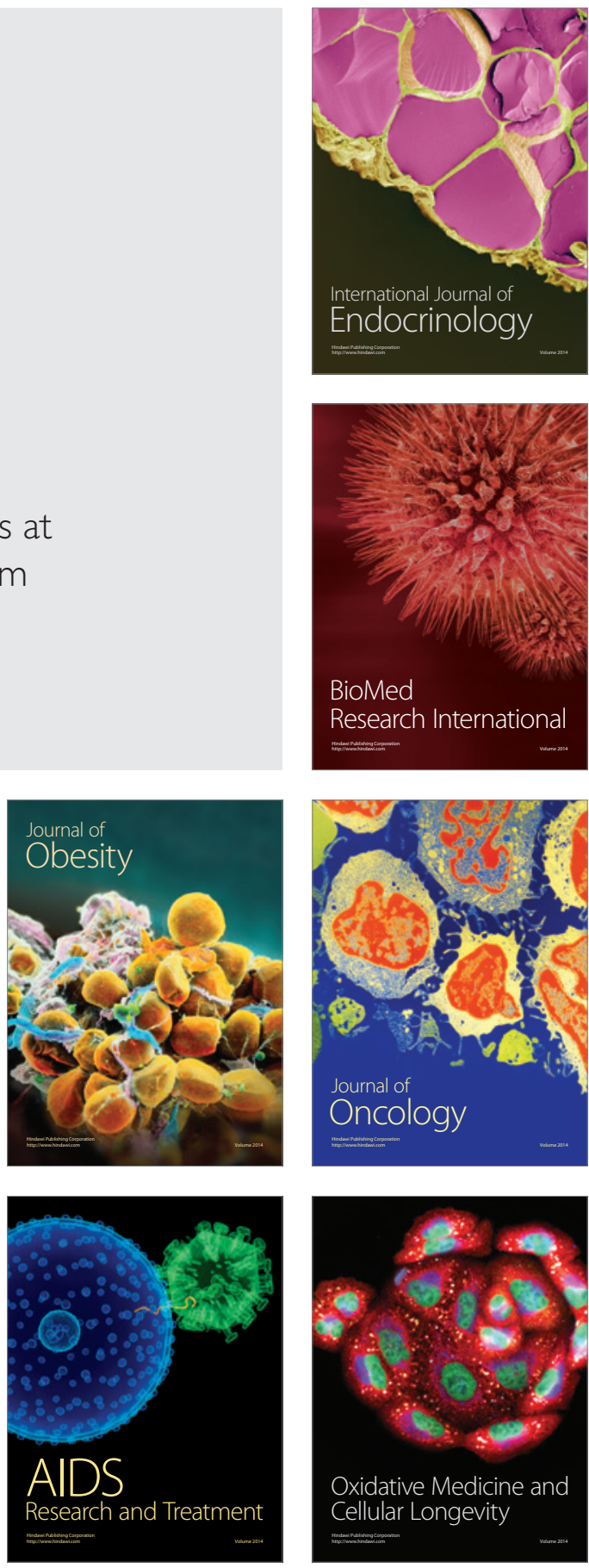